\title{
草坪无脊椎动物群落物种多样性及功能群研究
}

\author{
童春富 陆健健 \\ ( 华东师范大学河口海岸国家重点实验室, 上海 200062)
}

摘要: 本文采用扫网和样方法对草坪固定样地无脊椎动物群落进行了调查, 根据不同种类的营养情况进行了功能 群的划分, 并采用物种丰富度、Shannon-Wiener 指数、Hulbert 种间相遇概率、Pielou 均匀度指数等四种多样性指数对 群落及功能群的物种多样性进行了测度和分析。结果表明: 草坪无脊椎动物功能群组成具有一定的垂直分化; 不 同植被生长情况下功能群的组成及多样性具有一定的差异, 但无明显的规律性; 各功能群中, 捕食寄生性功能群的 多样性最高, 而植食性功能群的种类、数量最多, 但由于个别种数量的异常, 其多样性反而较低。植食性功能群与 捕食寄生性功能群在多样性、种类数及数量上呈现一定的互为消长关系。

关键词: 草坪, 无脊椎动物群落, 多样性, 功能群

中图分类号 :Q958 文献标识码 : A 文章编号 : 1005-0094(2002)02-0149-07

\section{Studies on species diversities and functional groups of invertebrate com- munities in an artificial turf}

TONG Chun-Fu , LU Jian-Jian

State Key Laboratory of Estuarine and Coastal Research , East China Normal University , Shanghai 200062

\begin{abstract}
Based on surveys of invertebrate communities on an artificial turf by the sweep net and quadrat sampling methods, we divided the species in the invertebrate community into three functional groups according to their trophic level. The species diversities of the community and functional groups were measured by species richness index, Shannon-Wiener index , Hulbert probability of interspecific encounter and Pielou evenness index. Species compositions of the functional groups were also analyzed. The functional groups differed in their vertical distributions. Species diversity and composition of the functional groups were different among plots with different vegetations. The predatory-parasitic group had the highest species diversity in the community, while the phytophagous group had more species and individuals than others, but its species diversity was not high as a result of some species with numerous individuals. There were dynamic relationships in species diversity , species number and individual number between the predatory-parasitic group and the phytophagous group.
\end{abstract}

Key words : artificial turf, invertebrate community, diversity , functional group

人工草坪是采用综合农业技术,在完全破坏了 天然植被的基础上，通过人为播种建植的人工草本 群落( 董世魁, 胡自治,2000)。作为城市绿化建设 的重要组成部分, 与草坪有关的动植物生态学研究 正日益受到人们的重视。但是传统的草坪科学通常 只涉及草坪植物学和草坪工程学, 只有在进行有害 生物防治时, 才涉及包括草坪无脊椎动物在内的草
坪动物的研究 (陈佐忠, 2000), 并且仅局限于工程 学的范畴, 基本不涉及多样性及功能群的研究。

作为世界级的国际机场, 浦东国际机场一期工 程建在原市郊的农业用地上, 飞行区草坪绿化面积 达 200 万 $\mathrm{m}^{2}$ 。因此在该区域草坪开展研究工作, 对 草坪生物多样性研究、有害生物的生态调控以及生 态学理论的发展都具有重要的价值。 


\section{1 研究方法}

\section{1 研究区域}

研究区域选在上海市东部新建的浦东国际机场 飞行区。该区位于长江口南岸,川沙南汇边滩。属 亚热带季风性气候, 温和湿润, 年平均气温 15.2 $15.7{ }^{\circ} \mathrm{C}$ 。全年雨量充沛, 年均降雨量 $1149 \mathrm{~mm}$ ( 上 海气象志编纂委员会,1997)。飞行区草坪为人工 栽种的单一的白车轴草 (Trifolium repens)。机场内 飞行区外有大量的闲置荒地, 生长有芦苇( Phragmites communis) 、加拿大一枝黄花 (Solidago canadensis) 等杂草, 并有积水的洼地。杂草有时也会蔓生至 飞行区。

\section{2 样地的选择}

在飞行区南北两端分别选择植被生长情况不同 的区域 :( I ) 纯白车轴草区域; ( II ) 白车轴草和以 喜旱莲子草 (Alternanthera philoxeroides) 等矮草为优 势种杂草的混合区域 (杂草盖度为 $50 \%$ 以上) ( III) 白车轴草和以加拿大一枝黄花等高草为优势 种杂草的混合区域 (杂草盖度为 $50 \%$ 以上)。各设 置一块 $50 \mathrm{~m} \times 100 \mathrm{~m}$ 的长方形样地, 南北两组形成 对照。同时平行的样地可以消除由于空间格局差异 对结果分析的影响。

在各样地四周建 $0.5 \mathrm{~m}$ 宽的空白隔离带, 以阻 断草层以下物种的交流。隔离带上的草连根拔除， 并插上小红旗作标记。

\section{3 取样}

在 1999 年 9 月 2000 年 8 月,采用灯光、糖浆 诱集(配方 红糖或白糖 3 份，醋 4 份，酒 1 份，水 2 份, 加少许敌敌畏, 混合后搅拌混匀) 以及网捕法对 飞行区昆虫进行详细调查的基础上,2000 年 9 月～ 11 月,在飞行区南北两端布设了上述 3 组样地, 各 样地每月取样 1 次。样地取样点的布设采用双对角 线法。各样地分别设 5 个采样点, 其中 1 个点位于 样地中部对角线交点位置, 其余 4 个点位于对角线 上,分别靠近矩形的四角, 大致呈中心对称。

取样点近草面及草面以上的无脊椎动物采用标 准捕虫网收集。每个取样点用捕虫网扫 10 复次，统 计昆虫的种类、数量。草面以下的无脊椎动物, 在去 除地上部分植被以后, 采用 $25 \mathrm{~cm} \times 25 \mathrm{~cm}$ 样方进行 取样调查, 拣取大型无脊椎动物。采样深度通常在
$25 \mathrm{~cm}$ 左右。

\section{4 数据处理及分析}

采用 Shannon-Wiener 多样性指数和 Pielou 均匀 度指数等多样性指数对无脊椎动物群落及功能群的 物种多样性进行测度(马克平,1994; 高宝嘉等， 1992 ;赵志模 郭依泉,1990)。

物种丰富度: $S$

Hulbert 种间相遇概率: PIE $=\sum\left[N_{i}\left(N-N_{i}\right) /\right.$ $N(N-1)]$

Shannon-Wiener 多样性指数: $H=-\sum P_{i} \ln P_{i}$

Pielou 均匀度指数: $J=H / \ln S$

其中 $N$ 为总个体数, $N_{i}$ 为第 $i$ 种的个体数, $P$ 为第 $i$ 种个体数占总个体数的比例。

\section{2 研究结果及分析}

\section{1 草坪无脊椎动物功能群的组成}

在样地调查期间共获取无脊椎动物标本 5206 头,分属 3 门 6 纲 15 目 36 科 64 种(李鸿兴等, 1987 ;萧采瑜等, 1977; 钟觉民, 1985; 中国农作物病 虫图谱编绘组, 1973; 江静波, 1982; 㐷钟琪, 1990; 浙 江动物志编辑委员会,1991)。根据对资源 (营养) 利用情况的不同, 将其划分为不同的功能群。

斜纹夜蛾 (Spodoptera litura)、黄卷叶蛾 (Pandaemis ribeana)、蜗牛 (Bradybena sp.) 等植食性种类 占总种数的 $57.8 \%$; 捕食寄生性种类占 $35.9 \%$, 其 中三突花蛛 (Misumenops tricuspidatus)、草间小黑蛛 (Erigonidium graminicola) 等蜘蛛占 $9.3 \%$ ，中华草 蛉 (Chrysopa sinica) 、步甲 (Nebria sp.) 等捕食性种 类占 $12.5 \%$ 黑侧沟姬蜂 (Casinaria nigripes)、蚜茧 蜂 (Aphidius sp.) 等寄生性天敌占 $14.1 \%$;蚯蚓( Oligochaeta opisthopora) 等其他分解者种类占 $6.3 \%$ 。

草坪无脊椎动物扫网调查结果如表 1 所示。植 食性功能群种类组成最为丰富, 涉及 2 门 3 纲 17 科, 种数占扫网调查总数的 $60.3 \%$,个体数占总数 的 $89.5 \%$;捕食寄生性功能群组成次之, 涉及 1 门 2 纲 5 目 13 科, 种数占扫网调查总数的 $37.7 \%$,个体 数占总数的 $10.3 \%$,且以昆虫纲种类较多;而分解 者功能群种类较少, 只有双翅目家蝇科家蝇 (Musca domestica) 1 种，个体数只占总数的 $0.2 \%$ 。

草坪无脊椎动物样方调查结果如表 2 所示。除 了分解者功能群, 其他功能群的种类数与个体数的 
表 1 草坪无脊椎动物群落扫网调查结果

Table 1 The investigation result of invertebrate communities in artificial turf by sweep net sampling

\begin{tabular}{|c|c|c|c|c|c|c|c|}
\hline $\begin{array}{c}\text { 功能群 } \\
\text { Functional group }\end{array}$ & $\begin{array}{c}\text { 门 } \\
\text { Phylum }\end{array}$ & $\begin{array}{c}\text { 纲 } \\
\text { Class }\end{array}$ & & $\begin{array}{c}\text { 目 } \\
\text { Order }\end{array}$ & $\begin{array}{c}\text { 科 } \\
\text { Family }\end{array}$ & $\begin{array}{l}\text { 种数 } \\
\text { No. of } \\
\text { species }\end{array}$ & $\begin{array}{c}\text { 数量 } \\
\text { No. of } \\
\text { individuals }\end{array}$ \\
\hline \multirow{18}{*}{$\begin{array}{l}\text { 植食性 } \\
\text { Phytophagous group }\end{array}$} & \multirow{16}{*}{$\begin{array}{l}\text { 节肢动物门 } \\
\text { Arthropoda }\end{array}$} & \multirow[t]{15}{*}{ 昆虫纲 Insecta } & \multirow{4}{*}{\multicolumn{2}{|c|}{ 鳞翅目 Lepidoptera }} & 粉蝶科 Pieridae & 2 & 2 \\
\hline & & & & & 夜蛾科 Noctuidae & 1 & 224 \\
\hline & & & & & 卷蛾科 Tortricidae & 1 & 105 \\
\hline & & & & & 螟蛾科 Pyralidae & 3 & 132 \\
\hline & & & \multirow{2}{*}{\multicolumn{2}{|c|}{ 半翅目 Hemiptera }} & 蝽科 Pentatomidae & 4 & 31 \\
\hline & & & & & 缘蝽科 Coreidae & 2 & 29 \\
\hline & & & \multirow{2}{*}{\multicolumn{2}{|c|}{ 双翅目 Diptera }} & 㿉蚊科 Cecidomyiidae & 2 & 2309 \\
\hline & & & & & 潜蝇科 Agromyzidae & 1 & 454 \\
\hline & & & \multirow{2}{*}{\multicolumn{2}{|c|}{ 同翅目 Homoptera }} & 叶蝉科 Cicadellidae & 5 & 77 \\
\hline & & & & & 蚜科 Aphididae & 1 & 1 \\
\hline & & & \multirow{2}{*}{\multicolumn{2}{|c|}{ 鞘翅目 Coleoptera }} & 叶甲科 Chrysomelidae & 3 & 42 \\
\hline & & & & & 步甲科 Caradibae & 1 & 2 \\
\hline & & & 膜翅目 & Hymenoptera & 蜜蜂科 Apidae & 1 & 1 \\
\hline & & & \multirow[t]{2}{*}{ 直翅目 } & Orthoptera & 蝗科 Acridiidae & 2 & 10 \\
\hline & & & & & 菱蝗科 Tetrigidae & 1 & 2 \\
\hline & & 蛛形纲 Arachnoida & 蜱螨目 & Acarina & - & 1 & 40 \\
\hline & 软体动物门 & 腹足纲 Gastropoda & 柄眼目 & & 巴蜗牛科 & 1 & 579 \\
\hline & Mollusca & & Stylomn & natophora & Bradybaenidae & & \\
\hline \multirow{13}{*}{$\begin{array}{l}\text { 捕食寄生性 } \\
\text { Predatory-parasitic } \\
\text { group }\end{array}$} & \multirow{13}{*}{$\begin{array}{l}\text { 节肢动物门 } \\
\text { Arthropoda }\end{array}$} & \multirow[t]{9}{*}{ 昆虫纲 Insecta } & 脉翅目 & Neuroptera & 草蛉科 Chrysopidae & 1 & 5 \\
\hline & & & \multirow[t]{4}{*}{ 膜翅目 } & Hymenoptera & 姬蜂科 Ichneumonidae & 2 & 41 \\
\hline & & & & & 螯蜂科 Dryinidae & 1 & 53 \\
\hline & & & & & 小茧蜂科 Braconidae & 4 & 33 \\
\hline & & & & & 小蜂科 Chalcididae & 1 & 2 \\
\hline & & & \multirow[t]{3}{*}{ 鞘翅目 } & Coleoptera & 漂甲科 Coccinellidae & 2 & 18 \\
\hline & & & & & 步甲科 Carabidae & 1 & 20 \\
\hline & & & & & 隐翅甲科 Staphilinidae & 1 & 4 \\
\hline & & & \multirow{5}{*}{$\begin{array}{l}\text { 双翅目 } \\
\text { 蜘蛛目 }\end{array}$} & Diptera & 寄蝇科 Tachinidae & 1 & 9 \\
\hline & & 蛛形纲 Arachnoida & & Araneida & 微蛛科 Erigonidae & 1 & 42 \\
\hline & & & & & 蟹蛛科 Thomisidae & 2 & 180 \\
\hline & & & & & 狼蛛科 Lycosodae & 1 & 10 \\
\hline & & & & & 跳蛛科 Salticidae & 2 & 50 \\
\hline $\begin{array}{l}\text { 分解者 } \\
\text { Decomposing group }\end{array}$ & $\begin{array}{l}\text { 节肢动物门 } \\
\text { Arthropoda }\end{array}$ & 昆虫纲 Insecta & 双翅目 & Diptera & 家蝇科 Muscidae & 1 & 8 \\
\hline
\end{tabular}

Note! - " 表示尚不确定 Something not confirmed

总数比扫网调查结果少得多, 这在一定程度上与调 查方法有关。同时,在功能群物种组成和数量比例 上与扫网调查结果有明显的差异。其中，植食性功 能群, 涉及 2 门 3 纲 6 目 11 科, 种类数占样方调查 总数的 $50 \%$,个体数占总数的 $39.6 \%$;捕食寄生性 功能群, 涉及 1 门 3 纲 3 目 7 科, 种类数占样方调查 总数的 $37.5 \%$,个体数占总数的 $42.7 \%$, 且以蛛形 纲种类居多;分解者功能群涉及 2 门 3 纲 3 目 3 科， 种类数占总数的 $12.5 \%$ ，个体数占总数的 $17.7 \%$ 。 两种调查方法所得功能群组成比例的差异如图 1 所 示。

在样方调查中, 分解者功能群无论种类还是个
体数量比例, 都明显高于扫网调查结果。捕食寄生 性功能群的个体数量所占比例也由扫网调查时的低 于植食性功能群变为高于植食性功能群。由于扫网 调查主要涉及近草面和草面以上的无脊椎动物, 而 样方调查主要涉及草面以下以及土壤中的无脊椎动 物, 因此两种调查方法的结果在种类组成和个体数 量上的差异, 可以在一定程度上反映物种及功能群 在垂直分布上的差异。

\section{2 草坪无脊椎动物功能群的物种多样性}

如表 3、表 4 所示, 草坪无脊椎动物各功能群的 物种多样性, 采用扫网和样方法调查结果相一致。 虽然植食性功能群物种数多于捕食寄生性功能群, 
表 2 草坪无脊椎动物群落样方调查结果

Table 2 The investigation result of invertebrate communities in artificial turf by quadrat sampling

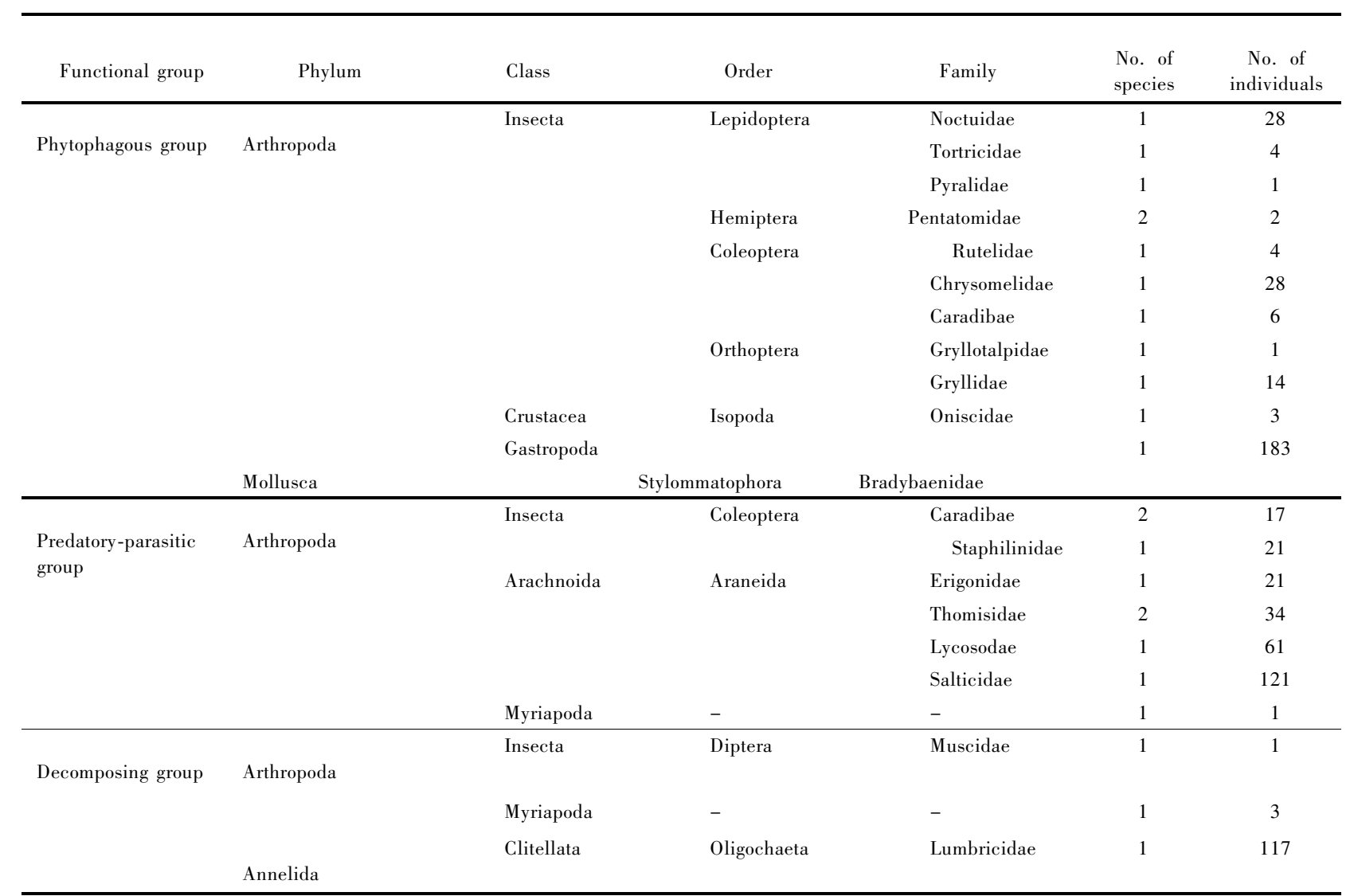

Note!" - "表示尚不确定 Something not confirmed

(a) 扫网调查的种类组成 Species composition by sweep net investigation

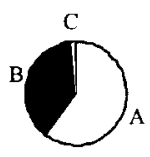

(c) 样方调查的种类组成 Species composition by quadrat investigation

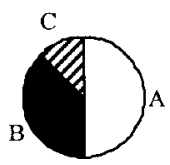

(b) 扫网调查的数量组成 Individual composition by sweep net investigation

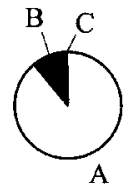

(d) 样方调查的数星组成 Individual composition by quadrat investigation

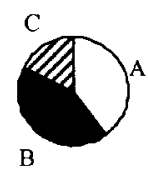

图 1 扫网和样方法调查结果的差异

Fig. 1 The difference in the results between sweep net and quadrat sampling investigation

A :植食性功能群 Phytophagous group B :捕食寄生性功能群 Predatory-parasitic group C: 分解者功能群 Decomposing group

表 3 扫网调查的物种多样性

Table 3 Species diversity by sweep net investigation

\begin{tabular}{lcccc} 
功能群 & \multicolumn{5}{c}{ 多样性指数 } & Diversity indices \\
\cline { 2 - 6 } Functional group & $S$ & $P I E$ & $H$ & $J$ \\
\hline 性 Phytophagous group & 32 & 0.7507 & 1.8565 & 0.5357 \\
寄生性 & 20 & 0.8676 & 2.3642 & 0.7891
\end{tabular}

Predatory-parasitic group

分解者 Decomposing group

$1 \quad 0 \quad 0$

Note $: S:$ 物种丰富度 Species richness index; PIE : Hulbert 种间相遇 概率 Hulbert probability of interspecific encounter ; $H$ : Shannon-Wiener 多样性指数 Shannon-Wiener diversity index; $J$ : Pielou 均匀度指数 Pielou evenness index

表 4 样方调查的物种多样性

Table 4 Species diversity by quadrat investigation

\begin{tabular}{|c|c|c|c|c|}
\hline \multirow{2}{*}{$\begin{array}{c}\text { 功能群 } \\
\text { Functional group }\end{array}$} & \multicolumn{4}{|c|}{ 多样性指数 Diversity indices } \\
\hline & $S$ & PIE & $H$ & $J$ \\
\hline 植食性 Phytophagous group & 12 & 0.5313 & 1.2262 & 0.4935 \\
\hline $\begin{array}{l}\text { 捕食寄生性 } \\
\text { Predatory-parasitic group }\end{array}$ & 9 & 0.7646 & 1.7386 & 0.7913 \\
\hline 分解者 Decomposing group & 3 & 0.0801 & 0.1986 & 0.1808 \\
\hline
\end{tabular}


但是捕食寄生性功能群的物种多样性要高于植食性 功能群。这主要是由于植食性功能群中个别种数量 的异常, 如稻掼蚊 (Contarinia sp.) , 其个体数就占 了扫网调查总数的 $44 \%$,严重破坏了整体的均匀 性, 从而使植食性功能群物种多样性降低, 而在 1999 年 9、10 月间, 就曾有斜纹夜蛾种群的大爆发。 同时，与前面分析相一致，样方调查中分解者功能群 物种多样性比扫网调查结果的物种多样性高。说明 分解者主要分布在草坪的草面以下,包括土壤中。

2.3 不同样地无脊椎动物功能群组成和物种多样性

不同样地扫网调查结果如表 5 所示。不同样地 相同功能群的种类数及个体数较为接近,基本为同 一数量级。而各样地无脊椎动物植食性功能群和捕 食寄生性功能群其种类数及个体数都呈现一定的互 为消长现象。

不同样地样方调查结果如表 6 所示。各样地捕 食寄生性功能群与植食性功能群种类数较为接近， 而样地 I 和样地 III 植食性功能群和捕食寄生性功 能群的个体数体现了一定的消长关系。样地 II 例

表 5 不同样地扫网调查结果

Table 5 The sweep net investigation result of species composition in different plots

\begin{tabular}{|c|c|c|c|c|c|c|}
\hline \multirow{2}{*}{$\begin{array}{c}\text { 功能群 } \\
\text { Functional group }\end{array}$} & \multicolumn{2}{|c|}{$\begin{array}{l}\text { 样地 I } \\
\text { Plot I }\end{array}$} & \multicolumn{2}{|c|}{$\begin{array}{l}\text { 样地 II } \\
\text { Plot II }\end{array}$} & \multicolumn{2}{|c|}{$\begin{array}{l}\text { 样地 III } \\
\text { Plot III }\end{array}$} \\
\hline & $\begin{array}{l}\text { 种类 } \\
N S\end{array}$ & $\begin{array}{c}\text { 数量 } \\
N I\end{array}$ & $\begin{array}{l}\text { 种类 } \\
N S\end{array}$ & $\begin{array}{c}\text { 数量 } \\
N I\end{array}$ & $\begin{array}{l}\text { 种类 } \\
N S\end{array}$ & $\begin{array}{c}\text { 数量 } \\
N I\end{array}$ \\
\hline 植食性 Phytophagous group & 24 & 1613 & 22 & 1114 & 23 & 1313 \\
\hline $\begin{array}{l}\text { 捕食寄生性 } \\
\text { Predatory-parasitic group }\end{array}$ & 13 & 134 & 18 & 172 & 16 & 161 \\
\hline 分解者 Decomposing group & 1 & 1 & 1 & 7 & 0 & 0 \\
\hline
\end{tabular}

Note : NS : 物种数 Number of species; $N I:$ 个体数 Number of individuals

样地 I 纯白车轴草样地 Plots of pure white clover turf; 样地 II : 以喜 旱莲子草等矮草为杂草优势种的混合样地 Plots with low grasses, such as alligator weed, as the dominant weeds; 样地 III : 以加拿大一枝 黄花等高草为杂草优势种的混合样地 Plots with tall grasses, such as common goldenrod, as the predominant weeds.

表 6 不同样地样方调查结果

Table 6 The result of species composition through sweep net investigation in different plots

\begin{tabular}{|c|c|c|c|c|c|c|}
\hline \multirow{2}{*}{$\begin{array}{c}\text { 功能群 } \\
\text { Functional group }\end{array}$} & \multicolumn{2}{|c|}{$\begin{array}{l}\text { 样地 I } \\
\text { Plot I }\end{array}$} & \multicolumn{2}{|c|}{$\begin{array}{l}\text { 样地 II } \\
\text { Plot II }\end{array}$} & \multicolumn{2}{|c|}{$\begin{array}{l}\text { 样地 III } \\
\text { Plot III }\end{array}$} \\
\hline & $\begin{array}{l}\text { 种类 } \\
N S\end{array}$ & $\begin{array}{c}\text { 数量 } \\
N I\end{array}$ & $\begin{array}{c}\text { 种类 } \\
N S\end{array}$ & $\begin{array}{c}\text { 数量 } \\
N I\end{array}$ & $\begin{array}{c}\text { 种类 } \\
N S\end{array}$ & $\begin{array}{c}\text { 数量 } \\
N I\end{array}$ \\
\hline 食性 Phytophagous group & 6 & 40 & 9 & 114 & 7 & 120 \\
\hline $\begin{array}{l}\text { 食寄生性 } \\
\text { redatory-parasitic group }\end{array}$ & 8 & 116 & 9 & 114 & 7 & 65 \\
\hline 解者 Decomposing group & 3 & 10 & 2 & 99 & 1 & 13 \\
\hline
\end{tabular}

外，其植食性功能群中蜗牛的数量过多，约占了植食 性功能群个体总数的 $80 \%$,其分解者功能群个体数 也明显多于其他样地, 这可能与喜旱莲子草等矮草 营造的局部小气候有关。

不同样地无脊椎动物功能群的物种多样性如图 2 所示。除了均匀度指数在反映样方调查结果的功 能群物种多样性时与其他指数有一定差异外, 3 种 多样性指数在描述各功能群物种多样性时基本一 致。

扫网调查的各样地无脊椎动物功能群物种多样 性如图 2(A) 所示。由于分解者功能群只有一个物 种, 因此不存在多样性的问题。各样地无脊椎动物 捕食寄生性功能群的多样性都明显高于植食性功能 群, 这与前面整体多样性分析相一致。植食性功能 群的多样性及均匀度是样地 II > 样地 III > 样地 I , 而捕食寄生性功能群的多样性及均匀度是样地 III > 样地 I > 样地 II 。如表 5 分析, 在各样地相同功能 群物种数和个体数较为接近的情况下, 这种多样性 的差异主要是由于不同种个体数量的不均衡, 即均 匀度差异造成的, 这与前面的分析相类似。

样方调查的各样地无脊椎动物功能群的物种多 样性如图 2(B) 所示。各样地捕食寄生性功能群的 物种多样性及均匀度要明显高于其他功能群。Hulbert 种间相遇概率和 Shannon-Wiener 多样性指数测 度结果表明, 植食性功能群的物种多样性是样地 I $>$ 样地 III > 样地 II , 捕食寄生性功能群的物种多样 性是样地 II > 样地 III > 样地 I , 而分解者功能群的 物种多样性是样地 I > 样地 II > 样地 III。同一样地 中各功能群的物种多样性是捕食寄生性功能群 $>$ 植 食性功能群 > 分解者功能群, 与扫网调查结果一致。 而 Pielou 均匀度指数测度的结果却有一定的差异。 植食性功能群的均匀度为样地 I > 样地 III > 样地 II , 分解者功能群的均匀度为样地 I > 样地 II (由 于样地 III 的分解者只有 1 种, 就无所谓均匀度的问 题), 都与多样性测度结果相一致; 但捕食寄生性功 能群的均匀度为样地 III > 样地 II > 样地 I ; 而在同 一样地中, 各功能群的均匀度在样地 I 出现与多样 性测度相悖的情况, 为捕食寄生性功能群 > 分解者 功能群 > 植食性功能群。这种多样性指数测度结果 的差异, 主要与不同指数所反映的多样性信息的侧 重面有关, 由多样性指数的函数性质决定。 
（a）Hulbert种间相遇概率 Hulbert probability of interspecific encounter

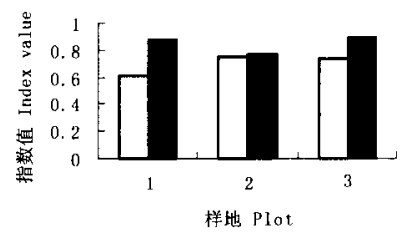

(a) Hu1bert种间相遇概率 Hulbert probability of interspecific encounter

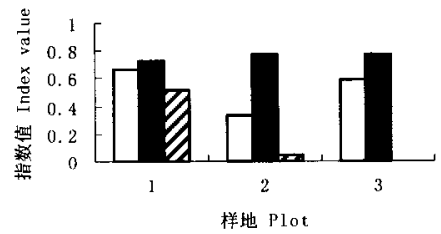

(b) Shannon-Wiener多样性指数 Shannon-Wiener diversity index

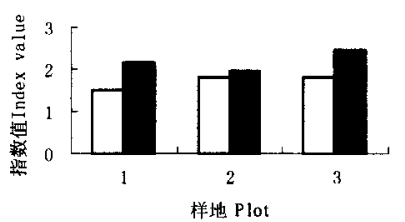

(A)

(b)Shannon-Wiener多样性指数 Shannon-Wiener diversity index

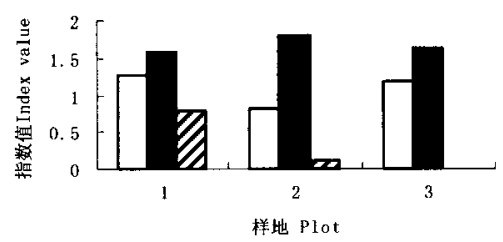

(B) (c) Pielou均匀度指数

Pielou evenness index

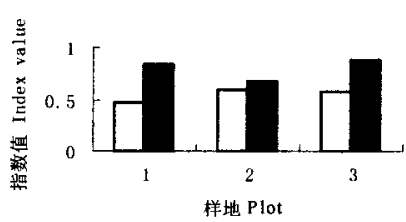

(c)Piclou均匀度指数 Pielou evenness index

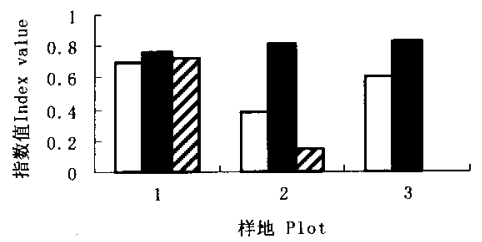

口植食性类群 Phytophagous group 口捕食寄生性类群 Predatory-parasitic group 曰分解者类群 Decomposing group

图 2 不同样地无脊椎动物功能群的物种多样性

Fig. 2 The species diversity of the invertebrate functional group in different plots

(A)不同样地扫网调查的功能群物种多样性 The sweep net investigation result of species diversity in different plots ; (B)不同样地 样方调查的功能群物种多样性 The quadrat investigation result of species diversity in different plots

从上述不同样地无脊椎动物功能群的多样性分 析中可以看出, 不同植被生长区域无脊椎动物的植 食性功能群和捕食寄生性功能群的组成及多样性， 包括均匀度在内, 存在某种互为消长的关系, 即不可 能在某一区域这两大功能群的多样性同时达到最 大。而区域的植被生长情况与各功能群多样性并无 简单的对应关系。有关植被与无脊椎动物的关系， 还有待于进一步的研究。

\section{3 结论}

\section{1 生物多样性的食物链控制}

对于生物多样性的食物链控制, 目前主要存在 下行控制 ( Top-down control) 和上行控制 (Bottom-up control) 两种观点。达尔文在 1859 年提出假设认 为, 高营养层通过抑制低营养层一种或几种竞争优 势种来提高低营养层的生物多样性（Darwin,1859）， 理论生态学家使这一假设正式成为学说 (Tilman， 1986 ;Leiobold ,1996)。现代生态学的许多实验也证 明了生物多样性这种自上而下控制作用的重要性 （May，1988），包括植物与植食动物，植食动物和捕 食者之间的这种控制作用。达尔文同时也提出假设 认为, 植被会通过改变植食动物而影响捕食者的多
样性( Darwin ,1859)。许多人认为生物多样性的这 种上行控制也是比较重要的 (Hunter \& Price, 1992 ; May，1988)。目前有关这方面的研究还有许多争 论。

本文研究表明, 在草坪无脊椎动物群落中, 捕食 寄生性功能群多样性最高, 捕食寄生性功能群和植 食性功能群的组成及多样性都存在一定的消长关 系。但样地 II 样方调查的结果是个例外。而且在每 一样地的植食性功能群中, 几乎都有个别种数量较 多, 并不能体现捕食寄生性功能群对优势植食性种 类的抑制作用。而不同区域的植被情况与无脊椎动 物功能群的多样性也并无简单的对应关系。因此， 不同营养层生物多样性之间的关系到底怎样, 草坪 食物链控制机制如何, 就目前的研究还不能作出简 单的论断。进一步的研究需要结合各种环境因子, 采用系统学的方法进行综合分析。

\section{2 草坪物种多样性的保持与恢复}

随着城市化进程的加快，原有栖息地的破坏，城 市绿化在区域原有生物多样性的保持与恢复中起着 举足轻重的作用。本文研究表明, 在草坪中, 无脊椎 动物种类极为丰富, 尤其是植食性功能群种类、数量 最多。但是如何在保持与恢复原有的生物多样性的 
同时，又能对有害生物，如爆发性的害虫实现有效的 控制，这还有待于进一步的研究，需要涉及上面提到 的食物链的控制机制以及多样性和稳定性的关系等 诸多问题。本文只是进行一些初步的基础性的研究 工作,为更深入地分析机理性的问题创造条件。

\section{参考文献}

陈佐忠, 2000. 草坪科学研究与草坪业发展几个问题的思 考. 草原与草坪, 1: 10 11

董世魁, 胡自治, 2000. 人工草地群落稳定性及其调控机制 研究现状. 草原与草坪, 3:3 8

冯钟琪著, 1990. 中国蜘蛛原色图鉴. 长沙: 湖南科学技术出 版社

高宝嘉, 张执中, 李镇宇, 1992. 封山育林对昆虫群落结构及 多样性稳定性影响的研究. 生态学报, 12(1): 1 6

江静波 (编著), 1982. 无脊椎动物学. 北京: 人民教育出版 社

李鸿兴, 隋敬之, 周士秀, 周勤, 孙洪国 (编著), 1987. 昆虫 分类检索. 北京: 农业出版社

马克平, 1994. 生物群落多样性的测度方法. 见: 钱迎倩, 马 克平 (主编), 生物多样性研究的原理与方法. 北京: 中 国科学技术出版社, $141 \sim 165$

上海气象志编纂委员会, 1997 . 上海气象志. 上海: 上海科
学院出版社

萧采瑜, 任树芝, 郑乐怡, 经希立, 穆强, 刘胜利, 陈汉华 (编 著), 1977. 中国蝽类鉴定手册 (半翅目异翅亚目) 第一 册、第二册. 北京: 科学出版社

赵志模, 郭依泉, 1990. 群落生态学原理与方法. 重庆: 科技 文献出版社重庆分社

浙江动物志编辑委员会, 1991. 浙江动物志 (甲壳类). 杭州: 浙江科学技术出版社, $127 \sim 141$

钟觉民编, 1985. 昆虫分类图谱. 南京: 江苏科学技术出版 社

中国农作物病虫图谱编绘组, 1973. 中国农作物病虫图谱 (1 11 分册). 北京: 农业出版社

Darwin C, 1859. On the origin of the species, Jhon Murray, London, UK

Hunter M D and P W Price, 1992. Playing chutes and ladders: heterogeneity and the relative roles of bottom-up and topdown force in natural communities. Ecology, 73: $724 \sim 732$

Leiobold M A, 1996. A graphical model of keystone predators in food webs: trophic regulation of abundance, incidence, and diversity patterns in communities. American Naturalist, 147: $784 \sim 812$

May R M, 1988. How many species are there on earth? Science, 241: $1441 \sim 1449$

Tilman D, 1986. A consumer-resource approach to community structure. American Zoologist, 26: $5 \sim 22$

(责任审稿人：周红章；责任编辑：间文杰)

\section{《长江重要鱼类生物多样性和保护研究》介绍}

《长江重要鱼类生物多样性和保护研究》( 上海科学技术出版社 2001 年 12 月出版) 是我国首卷系统阐述有关长江重要经 济鱼类生物多样性及其面临问题和保护对策的专著。该书共分 13 章, 约 20 万字。作者从长江生物多样性入手, 渐次深入到 主要经济和珍稀鱼类的遗传变异, 逐层讨论了就地保护、异地保护和开发利用等问题。该书从群体、个体、细胞及分子水平， 以及渔业生物学、群体遗传学和保护生物学相结合, 深入介绍和探讨了长江重要经济鱼类的遗传多样性与保护利用, 具有较 高的学术价值和实用参考价值。

作者李思发先生是上海水产大学的首席教授和博士生导师，本书汇集了作者长期主持国际合作和国家攻关项目研究的 成果, 凝集了作者为保护长江鱼类种质资源和使淡水资源得以持续发展而倾注的毕生精力。作者出于强烈的历史责任感, 意 欲通过此书, 唤起国人保护长江鱼类的意识，从而保护长江的生物多样性。

该书不但可供水产科技工作者、生物科学工作者和环境保护科学工作者参考,同时还将会对国内外生物多样性保护工作 产生深远的影响。 